\title{
MOVIMENTOS PENDULARES PARA TRABALHO E ESTUDO: ESTRATÉGIAS METODOLÓGICAS A PARTIR DOS CENSOS DEMOGRÁFICOS DE 2000 E 2010
}

Érica Tavares ${ }^{1}$

Jéssica Monteiro²

Resumo: Os movimentos da população no espaço constituem um processo social ligado à estruturação urbana e regional. Esses movimentos resultam das transformações sociais, políticas e econômicas, mas também influenciam a organização da sociedade no espaço. Nesse contexto, os movimentos pendulares são uma expressão da mobilidade cotidiana e estão relacionados às diferentes formas de apropriação do espaço urbano e regional. O objetivo desse texto é apresentar orientações metodológicas para análise dos movimentos pendulares para trabalho e estudo, a partir de informações dos Censos Demográficos brasileiros de 2000 e 2010, dada a sua relevância para os estudos demográficos, urbanos e regionais. Portanto, a metodologia adotada consiste em uma sistematização operacional para tratamento dos microdados censitários referentes aos movimentos pendulares.

Palavras-chave: Mobilidade Espacial. Movimento Pendular. Trabalho. Estudo. Censos Demográficos.

\section{COMMUTING FOR WORK AND STUDY: METHODOLOGICAL STRATEGIES FROM DEMOGRAPHIC CENSUS OF 2000 AND 2010}

Abstract: The population movements in space constitute a social process linked to the urban and regional structure. These movements result from social, political and economic transformations, but also influence the organization of society in space. In this context, the commuting is an expression of the daily mobility and are related to the different forms of appropriation of the urban and regional space. The objective of this text is to present some conceptual approaches and methodological orientations for the analysis of commuting for work and study, based on information from the Census of 2000 and 2010. Therefore, the methodology adopted consists of an operational systematization for treatment of census microdata relating to commuting. Keywords: Space Mobility. Commuting. Work. Study. Census.

\section{MOVIMIENTOS PENDULARES PARA TRABAJO Y ESTUDIO: ESTRATEGIAS METODOLÓGICAS A PARTIR DE LOS CENSOS DEMOGRÁFICOS DE 2000 Y 2010}

Resumen: Los movimientos de la población en el espacio constituyen un proceso social vinculado a la estructuración urbana y regional. Estos movimientos resultan de las transformaciones sociales, políticas y económicas, pero también influencian la organización de la sociedad en el espacio. En este contexto, los movimientos pendulares son una expresión de la movilidad cotidiana y están relacionados a las diferentes formas de apropiación del espacio urbano y regional. El objetivo de este texto es presentar orientaciones metodológicas para el análisis de los movimientos pendulares para trabajo y estudio, a partir de informaciones de los Censos

\footnotetext{
1 Universidade Federal Fluminense (UFF), Departamento de Ciências Sociais, Campos dos Goytacazes, Brasil, ericatavr@gmail.com, https://orcid.org/0000-0002-2427-5602.

2 Universidade Federal do Espírito Santo (UFES), Departamento de Geografia, Vitória, Brasil, jessicamonteirost@gmail.com, https://orcid.org/0000-0003-4612-4052.
} 
Demográficos brasileños de 2000 y 2010, dada su relevancia para los estudios demográficos, urbanos y regionales. Por lo tanto, la metodología adoptada consiste en una sistematización operacional para el tratamiento de los microdatos censales referentes a los movimientos pendulares.

Palabras claves: Movilidad Espacial. Movimiento Pendular. Trabajo. Estudio. Censos Demográficos.

\section{Introdução}

A mobilidade espacial da população é um processo social marcante na constituição do espaço urbano-regional, decorrente das transformações da sociedade, dos modelos econômicos, da localização das atividades produtivas, das chances de acesso aos bens e serviços públicos e privados, entre outros fatores. Faz parte das estratégias de localização no espaço urbano dos diferentes grupos sociais. Simultaneamente, a mobilidade espacial também influencia a organização da sociedade no espaço, já que a chegada ou mesmo permanência de certo contingente populacional numa determinada área pode modificar sua dinâmica populacional, suas condições de crescimento, as demandas por políticas públicas, acesso à educação, saúde, trabalho, moradia, entre outros elementos.

Os movimentos populacionais são bastante diversificados atualmente, especialmente pelo fato de que não há mais grandes eixos de movimento (expressivos fluxos populacionais para um mesmo destino e/ou saídas significativas de uma mesma origem) como ocorria no período de intensa urbanização no Brasil. Pode-se dizer que há uma diversidade de fluxos, com mecanismos explicativos mais peculiares centrados, sobretudo, na interseção entre os estudos geográficos, urbanos, demográficos e sociais.

Entre os processos de mobilidade espacial, a mobilidade cotidiana ganha cada vez mais expressividade na dinâmica urbana e regional e, embora envolva diversos tipos de movimento por variadas razões - como lazer, compras, acesso à trabalho, educação, saúde e outros bens e serviços - o levantamento de informações para todo o país com maior regularidade que permite aproximar-se dessa dimensão refere-se aos dados sobre movimentos pendulares obtidos através dos censos demográficos. Os movimentos pendulares são uma expressão dessa mobilidade cotidiana e das demandas e oportunidades principalmente de trabalho e estudo em uma região.

Nesse sentido, o presente artigo tem um objetivo instrutivo de caráter metodológico, pois trata sobre a importância de trabalhar com a dimensão da mobilidade espacial relacionada aos movimentos pendulares e as formas de tratar 
os microdados censitários no que se refere a tais deslocamentos. Essa abordagem se torna relevante no momento pré-censo 2020, a ser realizado pelo IBGE (Instituto Brasileiro de Geografia e Estatística). Diante das incertezas relativas à realização dessa grande operação de pesquisa, e mediante o fato de que as informações sobre mobilidade espacial e deslocamentos cotidianos apresentaram descontinuidades na trajetória do censo, a organização e pertinência desses dados precisam ser ainda mais enfatizadas.

Além disso, sistematizar o tratamento dessas variáveis nos censos anteriores contribui para esclarecer as possibilidades de utilização pretérita e futura, facilitando comparações, por exemplo, assim como permite que os novos pesquisadores sobre o tema possam reconhecer suas potencialidades e limitações. Aliás, a proposta de um artigo com esse objetivo surge justamente dos questionamentos de novos pesquisadores ou mesmo daqueles que, embora mais experientes no universo da pesquisa, começaram a trabalhar com o tema recentemente.

Para essa abordagem, o trabalho está organizado em duas seções com objetivos definidos. A primeira relata brevemente alguns elementos sobre a relação dessas informações com temas ligados aos estudos geográficos, demográficos e urbanos, destacando sua importância na análise dos processos de estruturação urbana e regional. Na segunda seção, trabalha-se operacionalmente com os dados sobre os movimentos pendulares no Brasil. O objetivo é apresentar estratégias operacionais para análises e possibilidades de comparação dos movimentos pendulares para trabalho e estudo registrados em 2000 e 2010, a partir dos Censos Demográficos brasileiros realizados pelo IBGE, a fim de contribuir também para a incorporação dos novos dados que esperamos serem disponibilizados a partir do Censo Demográfico de 2020.

\section{Os movimentos pendulares e a relação com os processos de estruturação urbana e regional: possibilidades de análise}

Geralmente quando se pensa em movimento no campo dos estudos populacionais, a variável mais comum é a migração. Vários artigos sobre dinâmica populacional e migrações em grandes aglomerados urbanos (BAENINGER, 1998; CUNHA, 2002; RIGOTTI, 2008; BRITO, 2009) apontaram a importância da dimensão da mobilidade para explicar a dinâmica populacional, uma vez que as 
taxas de fecundidade e mortalidade seguiram apresentando expressivo declínio durante o século $X X$ no Brasil.

Seja numa abordagem histórico-estruturalista (SINGER, 1977), ou a partir de um enfoque neoclássico-funcionalista (LEE, 1980), ou mesmo em uma proposta que busca articular um olhar micro e macro (WOOD, 1982), durante bastante tempo a dimensão mais acionada ao se falar em mobilidade do trabalhador e acesso a oportunidades de inserção no mercado de trabalho foram as migrações. Ou seja, os dados sobre migração eram usados para dimensionar a mobilidade para trabalho.

Atualmente, a clássica relação migração-trabalho ainda apresenta sua pertinência, entretanto, diante do processo de urbanização e constituição de uma diversidade de aglomerações urbanas, a mobilidade do trabalhador também sofreu certas alterações, seja a partir de uma migração urbano-urbana, seja a partir de deslocamentos diários entre a residência e o local de trabalho. De qualquer forma, deve-se reconhecer que a realidade urbana atual complexifica as possíveis explicações para os movimentos de população.

A análise da mobilidade espacial esteve, ao longo do tempo, relacionada a estudos demográficos, urbano-regionais e geográficos, mas também passa a ser incorporada por outras áreas do conhecimento, como pela sociologia. Segundo Urry (2007), a sociedade contemporânea se organiza em torno de diversas práticas que geram um constante movimento de ideias, informações, objetos e pessoas. Ou seja, as pessoas estão inseridas em um conjunto dinâmico de relações, estruturas e instituições, nas quais a mobilidade se torna um aspecto central para essa inserção. Por isso também é preciso ressaltar as dimensões sociológicas e geográficas ligadas ao processo, como os aspectos socioculturais das pessoas e dos lugares de origem e destino. Para analisar um processo social, como os movimentos populacionais, deve-se compreendê-lo em sua perspectiva histórica e na relação que apresenta com a sociedade e o espaço em que ocorre.

Em publicação do IBGE sobre os deslocamentos populacionais (OLIVEIRA, 2011), os pesquisadores expõem a demanda por explicações teóricas para os novos processos que têm ocorrido no Brasil. Entre os fenômenos apontados, ressaltam que os movimentos pendulares passam a assumir maior relevância nas estratégias de melhoria de vida ou mesmo de sobrevivência, não mais restritos aos grandes aglomerados urbanos. Inclusive para este tipo de mobilidade espacial ocorreu o inverso do movimento migratório, já que apresenta uma ampliação das distâncias percorridas e passa a envolver cada vez mais aglomerações no interior dos estados. 
A importância de considerar os dados sobre mobilidade espacial está na fundamentação conceitual que suscitam, enquanto um processo social, mas também no aporte empírico que proporcionam, ao permitir debater temas atuais sobre a realidade urbana, tanto em termos conceituais e operacionais, como também aqueles ligados à implementação de políticas públicas (RODRIGUEZ, 2011).

Moura et al. (2013) também indicam que os processos ligados aos movimentos pendulares "criam, ou complexificam, demandas para a provisão e adequação de infraestrutura e serviços, quer propriamente para os deslocamentos (...) quer para reforço das funções de recepção ou de apoio às pessoas que permanecem" (ibid, p. 683). Ao mesmo tempo em que destacam a importância de "políticas públicas que facilitem e agilizem esses deslocamentos e enfrentem, com soluções adequadas, as consequências familiares que acarretam" (ibid, p. 683), também apontam a necessidade de "políticas que criem condições para que se reverta a disjunção moradia-trabalho-estudo, resultando em aglomerações com mais subcentralidades, menores assimetrias entre os municípios e maior fluidez para a circulação de pessoas e mercadorias" (ibid, p. 683). Por isso, o estudo de tais movimentos é muito importante para análise e implementação de políticas públicas, especialmente aquelas relacionadas ao trabalho, à educação e à mobilidade.

\section{Os movimentos pendulares para trabalho e os processos de segmentação residencial e econômica do espaço}

O movimento pendular para trabalho é um tipo de mobilidade espacial estreitamente ligado a dimensões urbano-regionais e a organização econômica do espaço regional. As informações sobre este tipo de deslocamento também constituem importante referencial para analisar as aglomerações urbano-regionais, a metropolização e a expansão urbana, assim como os processos de formação de centralidades e periferias urbanas (MOURA et al., 2005; SILVA, 2013).

A mensuração desses movimentos pendulares permite a "apreensão de novas dimensões do processo de reestruturação do espaço intrametropolitano, podendo contribuir para revelar o alcance das novas formas espaciais urbanas" (MOURA et al., 2005, p. 121). Lobo (2016, p. 289), aponta que as transformações na dinâmica das áreas metropolitanas são caracterizadas por "alta densidade de movimento pendular - considerada como principal indicador da mobilidade e conectividade", o que definiria um novo conceito de "área metropolitana", 
destacando a relevância dos deslocamentos para trabalho e estudo para a compreensão dos processos de metropolização, uma vez que estes "permitem verificar o grau de extensão da circularidade de pessoas em uma determinada região" (LOBO, 2016, p. 289). O avanço tecnológico, principalmente no setor de transportes, também contribui com essa alta densidade de movimento pendular, como sugerem Beaujeu-Garnier (1980), Moura et al. (2005), Jardim (2011), Santos (2014).

Ao explorar uma pesquisa sobre deslocamentos pendulares na Região Metropolitana de São Paulo, Moura et al. (2005) afirmam que:

Os resultados dessa análise demonstram o relacionamento inverso entre a espacialização das atividades econômicas e os locais de moradia, pois geram a configuração de locais com funções distintas, em decorrência do acesso diferenciado à terra e da divisão regional do trabalho metropolitano. Além disso, reiteram sua importância para o entendimento do papel desses deslocamentos diários e implicações no processo de configuração e estruturação da aglomeração metropolitana (MOURA et al., 2005, p. 129).

As centralidades dessas áreas são facilmente perceptíveis e contribuem também na identificação dos processos de segmentação dos locais de moradia e trabalho, o que se traduz na divergência de localização das atividades econômicas e, consequentemente, dos postos de trabalho, em relação à localização da população - segmentação residencial e uma segmentação econômica do espaço.

Sendo assim, de forma integrada, o movimento pendular para trabalho também está ligado à organização social na escala da cidade, às formas seletivas de uso e apropriação do espaço. O acesso às oportunidades pode ser potencializado por mecanismos relacionados às condições de mobilidade para trabalho, tal acesso depende da posse de capital social, econômico, cultural. "A falta de capital intensifica a experiência da finitude: ela prende a um lugar" (BOURDIEU, 1997, p. 164). O acesso às oportunidades também passa pela capacidade de uma pessoa ou de um domicílio em acionar os ativos disponíveis em distintos âmbitos socioeconômicos, a fim de aprimorar sua situação social e qualidade de vida ou evitar sua piora nessas condições (KAZTMAN, 1999). A mobilidade cotidiana pode ser compreendida com um dos mecanismos que permitem acessar uma estrutura de oportunidades desigualmente distribuída no espaço, uma estratégia de organização dos indivíduos e famílias para garantia da reprodução social. Os movimentos também devem ser compreendidos na relação dialética existente entre centralidades e periferias, mobilidade e imobilidade, segregação e fragmentação. 
A relação centro-periferia ainda contribui para compreender os movimentos populacionais cotidianos, uma vez que os grandes fluxos ainda permanecem das áreas com menos empregos para áreas onde há maior concentração destes. Pereira e Herrero (2009) buscaram um aprofundamento em nível teórico a respeito dos movimentos pendulares. No que se refere à definição do movimento pendular para trabalho, os autores ainda seguiram a definição baseada no levantamento de dados censitários no Brasil, mas avançaram em questões qualitativas sobre o fenômeno, assim como nos processos que o originam, que seriam a concentração urbana, a saturação urbana e desconcentração produtiva. Entre esses, a concentração urbana, seria justamente essa "intensificação da diferenciação espacial entre áreas residenciais e de trabalho, sendo marcado pela periferização urbana da população, particularmente de baixa renda, e grande centralidade do núcleo urbano (...)" (PEREIRA e HERRERO, 2009, p. 16).

Essa lógica centro-periferia deve ser analisada também a partir da fragmentação urbana, uma vez que, dada às mudanças na territorialização da estrutura produtiva, do emprego e da moradia, há uma dispersão tanto da população quanto dos postos de trabalho (não na mesma medida), gerando novas centralidades e novas periferias. Os clássicos espaços da periferia até os anos 80 ou mesmo 90 nas grandes metrópoles sofreram significativas transformações, passando também a configurar-se como espaços de trabalho (LAGO, 2007).

Como exemplo, no caso da Região Metropolitana do Rio de Janeiro (RMRJ), os movimentos pendulares apresentaram mudanças significativas na primeira década do século XXI, aumentando tanto o volume quanto a proporção de pessoas que realizam deslocamentos intermunicipais para trabalho. Esse crescimento ocorreu em todos os municípios. A metrópole passou a ter quase um milhão de pessoas se deslocando cotidianamente entre municípios, fora os que se movimentam internamente nestes. Foi observado que, embora tenha ocorrido aumento absoluto, diminuiu a participação daqueles que saem dos demais municípios da RM para trabalhar no núcleo, de aproximadamente $65 \%$ para $61 \%$. Além disso, apesar do número mais reduzido se comparado aos outros deslocamentos e de ter pequena participação no total (4,7\% em 2010), a quantidade de pessoas que sai do núcleo para trabalhar nos demais municípios dobrou na década de 2000 (TAVARES, 2012, p. 20), também houve uma intensificação dos movimentos para além da metrópole. 
Tais mudanças no clássico padrão de concentração urbana, baseado no modelo centro-periferia, podem estar ligadas a dois outros processos também apontados por Pereira e Herrero (2009), a saturação urbana marcada pela "saturação de centros urbanos (pela decadência do parque imobiliário ou pelo desgaste das condições destes centros em termos ambientais, de segurança e transporte) e pela expansão de oferta imobiliária de alto padrão em regiões menos centrais" (ibid, p. 17); e o processo de desconcentração produtiva, que ocorre "quando, por vantagens logísticas, incentivos fiscais, restrições pela legislação ambiental etc., empresas reavaliam sua localização em busca de locais menos centrais das redes urbanas" (ibid, p. 18). Vale ressaltar que os movimentos originados por diferentes processos também são marcados por um perfil socioeconômico diferenciado da população que se move.

Uma breve referência a essas transformações já indica que cada vez mais é necessária uma análise que associe a mobilidade residencial com a mobilidade cotidiana, pois tanto os movimentos migratórios quanto os pendulares aumentaram consideravelmente na própria periferia metropolitana e em áreas do interior dos estados. Diante das mudanças apontadas, também tem sido interessante analisar tais movimentos e a distribuição dos grupos populacionais envolvidos em processos de mobilidade espacial em escalas mais reduzidas.

A mobilidade pendular geralmente abarca distâncias mais limitadas, por serem movimentos cotidianos, mas também podem envolver movimentos entre regiões e estados, assim como ser realizado de um bairro a outro, mas com origem e destino em municípios diferentes. Trabalhos como o de Cunha et al. (2006), Pereira (2006) e Lima (2015) contemplam tanto deslocamentos intermunicipais como intramunicipais, considerando as trocas populacionais constantes entre diferentes bairros do mesmo município. A distribuição da população que realiza movimento pendular na escala interna da cidade também é possível, conforme estudo de Silva (2013), através dos microdados censitários.

Essa é uma problematização importante referente aos movimentos pendulares, é preciso pensar sobre as escalas territoriais e as distâncias e temporalidades dos movimentos. Cunha et al. (2013, p. 441), ao tratar sobre a mobilidade pendular na macrometrópole paulista, também apontam que, diante das novas configurações urbano-regionais, reforça-se "a necessidade da análise espacial compreender os movimentos do território, além dos limites das divisões administrativas e conceituais da cidade". Além disso, é importante uma análise 
combinada sobre a saída e a atração dos diferentes espaços, por isso as orientações metodológicas tratam a forma de computar os dados para as duas dimensões.

\section{Os movimentos pendulares para estudo e os processos de segmentação das oportunidades educacionais}

Embora haja um maior volume de deslocamentos relacionados a questões laborais, a busca por oportunidades educacionais também é motivação para deslocamentos cotidianos intermunicipais. O padrão espacial da localização dos estabelecimentos de ensino, de forma concentrada em determinados espaços, a gratuidade e a qualidade das instituições contribuem para a ocorrência de deslocamentos frequentes entre residência e unidade de ensino por parte de um amplo número de estudantes. Tanto o acesso como a permanência desses estudantes nas escolas e universidades são afetados pelas dificuldades que eles enfrentam por ter que se deslocar diariamente entre suas residências e as instituições de ensino. Esses estudantes que ultrapassam a fronteira administrativa de seu município de residência para estudar em outro foram denominados "estudantes pendulares" por Tavares (2016).

$\mathrm{Na}$ análise sobre esse tipo de deslocamento não se pode desconsiderar os processos decisórios que envolvem a resistência e adaptação inicial dos estudantes pendulares, como expresso no conceito "geografia de oportunidades", desenvolvido por Galster e Killer (1995), que busca associar o processo de tomada de decisões ao contexto geográfico de cada indivíduo. Alves et al. (2010) trabalham com esse conceito destacando que existem variações objetivas e subjetivas que podem alterar o processo de tomada de decisões:

A Geografia Objetiva de Oportunidades, isto é, a estrutura, qualidade e 0 acesso às oportunidades (sistemas sociais, mercados e instituições), variam entre uma região e outra. Ao mesmo tempo, a Geografia Subjetiva de Oportunidades (os valores, anseios, preferências e percepções subjetivas acerca das oportunidades e dos potenciais resultados da tomada de decisões) também varia geograficamente. A Geografia Subjetiva limita as oportunidades que, de fato, estão acessíveis aos indivíduos (ALVES et al., 2010, p. 69).

Nesta concepção, as oportunidades de acesso às unidades de ensino de qualidade por famílias de classes mais populares podem ser limitadas tanto pela indisponibilidade de escolas e universidades, como também por não estarem dentro das "opções possíveis", já que os valores e as expectativas são diferenciados em 
cada família, que apresentam características econômicas, culturais e sociais distintas. Ou seja: a educação não é percebida e vivenciada da mesma maneira em todas as famílias.

Uma associação entre oportunidades de qualificação e deslocamento populacional foi feita por Braga e Matos (2017, p. 74). Os autores observaram que "os novos migrantes das metrópoles tiveram acesso à escolaridade nas áreas de origem", ou seja, tem acontecido uma expansão geral da escolaridade para além das metrópoles, o que podemos chamar de interiorização educacional. Esse processo pode diminuir o fluxo para estudo em direção à metrópole: "considerando a migração como um esforço de investimento em capital humano, a ampliação das oportunidades de qualificação em municípios não-metropolitanos aumenta o risco associado ao movimento para as metrópoles" (ibid, p. 74). Da mesma forma, esse processo de interiorização também afeta os movimentos pendulares para estudo.

Também é preciso considerar que a mobilidade pendular para estudo está atrelada às políticas educacionais vigentes, em nível nacional ou regional. No caso do Brasil, os deslocamentos em busca de oportunidades educacionais, principalmente de nível superior, têm se intensificado nos últimos anos, processo relacionado à expansão da oferta de ensino superior a nível nacional, entre outros fatores. Essa expansão vem ocorrendo no Brasil a partir dos anos 2000, tanto na esfera pública, quanto na privada, com a implementação de programas como PROUNI, REUNI e FIES ${ }^{3}$ que ampliam as vagas e o acesso à educação superior.

Outro projeto relacionado à educação superior merece destaque, pois tem potencializado o deslocamento de estudantes pelo território brasileiro. Trata-se do Sistema de Seleção Unificada (SISU), um sistema coordenado pelo Ministério da Educação (MEC) pelo qual instituições públicas de ensino superior disponibilizam vagas em seus cursos presenciais. Os candidatos participantes do Exame Nacional do Ensino Médio (ENEM) podem se inscrever em quaisquer universidades do Brasil, podendo escolher até duas opções entre as vagas ofertadas pelas instituições participantes (SISU, 2016). Esse projeto facilita aos estudantes a inscrição e acompanhamento das etapas do processo seletivo das universidades, mesmo que elas estejam distantes de seu local de residência. As provas são realizadas no próprio município dos candidatos, que, após aprovados, se articulam e podem se

\footnotetext{
${ }^{3}$ Programa Universidade para todos - PROUNI (Lei № 11.096, de 13 de janeiro de 2005); Programa de apoio à planos de Reestruturação e Expansão das Universidades Federais - REUNI (Decreto № 6.096, de 24 de abril de 2007); Programa de Financiamento Estudantil - FIES (Lei oㅜ 10.260, de 12 de julho de 2001).
} 
organizar para realizar deslocamentos pelo território para frequentar o curso pretendido.

Sobre a mobilidade populacional para fins de estudo, destacam-se os trabalhos de Pereira (2006) e Lima (2015), que trazem contribuições acerca dos estudantes pendulares da educação básica (nível médio), das redes públicas de ensino em Brasília (DF) e Natal (RN), respectivamente. Em ambas as abordagens, foram detectadas uma incoerência espacial entre a oferta e a demanda pelos serviços de educação, assim como foi destacado o papel chave dos deslocamentos pendulares na compreensão dos aglomerados urbanos e suas dinâmicas. Análise específica sobre movimentos espaciais de estudantes feita por Tavares e Tavares (2014), indica que a renda domiciliar e a faixa etária dos estudantes são elementos importantes para efetivação dos deslocamentos, pois as famílias com renda mais alta têm maior representatividade nos movimentos em busca de oportunidades educacionais em outros municípios, assim como o grupo de jovens e adultos, com idade entre 15 a 24 anos. Ou seja, a mobilidade é um ativo para acessar as oportunidades educacionais, porém ela própria também pode depender das condições sociais e econômicas para ser realizada.

Apesar dos deslocamentos para fins de estudo ocorrerem em todos os níveis educacionais, o que predominam são os deslocamentos para cursar a educação superior (graduação e pós-graduação), uma vez que "cursos mais básicos tendem a ser realizados mais próximos do local de residência, pois apresentam uma maior capilaridade em sua distribuição no território, constituindo, inclusive, obrigação constitucional da esfera municipal" (IBGE, 2012, p. 82). Como as Instituições de Ensino Superior são mais raras no território, consequentemente existe necessidade de deslocamento para outros municípios que ofereçam cursos desse nível.

Embora não seja pretensão nesse texto, cabe ressaltar que, se os estudos relativos aos movimentos pendulares para trabalho ainda são, em sua maioria, de cunho empírico e descritivo, a análise sobre os movimentos pendulares para estudo é ainda mais afetada por essa questão. Torna-se necessário realizar aprofundamentos teóricos (abstratos) a respeito dos temas em tela. Para este artigo, o objetivo é considerar a relevância e os cuidados metodológicos para tratar sobre a mobilidade pendular no Brasil, mas não se pode desconsiderar que os movimentos populacionais urbanos estão estreitamente relacionados às potencialidades e aos constrangimentos da estrutura urbana - acesso à moradia, trabalho, educação, lazer, entre outros. Sendo assim, reconhecemos a importância de compreendê-la 
em sua dimensão social e na relação estabelecida com os lugares de origem e destino, por isso a abordagem realizada até aqui. Em seguida, apresentamos algumas orientações metodológicas para o tratamento das informações sobre movimento pendular no Brasil a partir dos censos demográficos.

\section{Estratégias metodológicas para mensuração dos movimentos pendulares para trabalho e estudo a partir dos censos demográficos de 2000 e 2010}

A partir dos apontamentos conceituais colocados, reconhecemos que, ao trabalhar com indicadores de movimento pendular, estamos nos aproximando da dimensão da mobilidade espacial, ou seja, os dados constituem uma proxy da mobilidade espacial cotidiana, afinal as dimensões conceituais e a própria realidade ultrapassam os dados utilizados.

A principal fonte de dados sobre o tema no Brasil são os Censos Demográficos, grande pesquisa realizada pelo IBGE a cada dez anos com abrangência em todo território nacional. A possibilidade de comparação analítica entre os censos permite identificar diversos aspectos da dinâmica populacional em nível nacional, estadual ou municipal. Por isso, a produção de informações sobre os movimentos pendulares é tão importante.

Realizado desde 1872, a pesquisa censitária no Brasil só tratou da mobilidade pendular nos censos de 1970, 1980, 2000 e 2010. Houve uma lacuna na coleta dessa informação uma vez que o censo de 1991 não contemplou o movimento pendular. Em 2000 a informação voltou a ser coletada de maneira agregada para deslocamentos para trabalho e estudo, com uma única pergunta. Em 2010, no último censo realizado, foi feita uma revisão metodológica que levou em consideração as demandas dos usuários dos dados dos censos demográficos, resultando em algumas alterações no formato da investigação do tema ao incorporar novas perguntas sobre movimentos pendulares ao questionário da amostra. O tema foi desmembrado em dois blocos: um para trabalho; e outro para estudo - o que tornou possível obter a distribuição dos trabalhadores e estudantes que se deslocam entre municípios e, consequentemente, uma análise mais detalhada desses movimentos ${ }^{4}$.

Com base nos resultados do Censo 2010 e estudos recentes do IBGE quanto aos deslocamentos entre municípios para estudo e trabalho, pode-se perceber a relevância dessas informações para quantificar e qualificar esses fluxos,

\footnotetext{
${ }^{4}$ Para o Censo 2020, a pergunta permanecerá separada em dois blocos.
} 
assim como para compreender as relações funcionais que são estabelecidas entre as localidades e planejar atividades em níveis local e regional. Segundo o IBGE (2012):

O conhecimento da intensidade desses fluxos, além de facilitar a racionalização dos sistemas de transporte, permite melhorar a qualidade de vida das populações, pela redução dos custos de transporte, do tempo gasto nos deslocamentos e da diminuição dos níveis de poluição, entre outros (IBGE, 2012, p. 79).

Os resultados da amostra do Censo Demográfico 2010 indicam que, das 59.565.188 pessoas que declararam frequentar escola ou creche ${ }^{5}$ no Brasil, 4.301.914 o faziam em outro município, o que representa $7,2 \%$ do total. Para estudar em país estrangeiro o total foi de 37.059 pessoas em deslocamento.

Quanto ao deslocamento para trabalho, das 86.353 .839 pessoas de 10 anos ou mais de idade que declararam estar ocupadas na semana de referência, 10.146.721 tinha como local de exercício do trabalho principal, outro município, diferente ao de sua residência, o que representa $11,8 \%$ do total. A maioria, como esperado, trabalha no próprio município de residência, que corresponde a $87,2 \%$ do total. Para trabalhar em país estrangeiro foram 35.984. E ainda, há aqueles que trabalham em mais de um município ou país (903.585).

\section{Variáveis relacionadas aos movimentos pendulares a partir dos Censos 2000 e 2010}

Como visto, o movimento pendular está geralmente ligado à expansão de uma determinada região que exerce influência, em termos de centralidade, sobre o acesso ao mercado de trabalho, às instituições de ensino e saúde, e aos bens, serviços e equipamentos de lazer, entre outros elementos da estrutura urbana.

Abarcar todos esses elementos para apreender a mobilidade cotidiana através do uso de fontes de dados secundários é difícil. No caso dos censos demográficos, o movimento pendular é avaliado apenas no que se refere à inserção no mercado de trabalho ou acesso às oportunidades educacionais. Portanto é de suma importância o levantamento separado de dados para estas dimensões. A pergunta sobre movimentos pendulares nos censos demográficos brasileiros sofreu algumas alterações ao longo do tempo. Neste trabalho, vamos nos concentrar nos Censos Demográficos de 2000 e 2010.

\footnotetext{
${ }^{5}$ De acordo com IBGE (2012), considera-se escola ou creche todos os níveis educacionais (da creche a pós-graduação, inclusive mestrado e doutorado).
} 
Em 2000, a pergunta era a mesma para movimento de trabalho e estudo, e essa era uma grande limitação. Através da variável V4276 dos microdados da amostra é possível identificar o "Município/Unidade da Federação ou País estrangeiro em que a pessoa trabalha ou estuda", conforme a tabela 1.

Tabela 1 - Variável de movimento pendular no Censo Demográfico Brasileiro - 2000 CÓDIGO DO MUNICÍPIO E UNIDADE DA FEDERAÇÃO OU PAÍS ESTRANGEIRO QUE TRABALHA OU ESTUDA

V4276 Município/Unidade da Federação ou País estrangeiro em que a pessoa trabalha ou estuda.

- As descrições encontram-se no arquivo "Municípios e País Estrangeiro V4276.xIs"

Fonte: Dicionário de Variáveis - Censo Demográfico de 2000 (IBGE).

A partir desta questão, não era possível saber diretamente se o movimento era para um motivo ou para outro. Uma proxy desta distinção é identificar se a pessoa só trabalhava ou só estudava com outras variáveis do censo ${ }^{6}$. Sendo assim, se a pessoa realiza movimento pendular e apenas trabalha, obviamente 0 movimento era para trabalho. Se a pessoa realiza movimento pendular e somente estuda, o movimento era por motivo de estudo. A indefinição se dá quanto àqueles que trabalham e estudam e realizam movimento pendular. Para se ter uma ideia, no Brasil, dos cerca de 7 milhões $^{7}$ de pessoas que faziam movimento pendular em $2000,73 \%$ eram apenas trabalhadores, $17 \%$ eram apenas estudantes e $10 \%$ eram trabalhadores e estudantes simultaneamente. Ou seja, apenas para estes últimos, não se sabe se o movimento era para trabalho ou estudo.

Sendo assim, com os dados do Censo 2000, as pessoas que realizam movimento pendular, podem ser divididas em três grupos: só trabalham, só estudam, trabalham e estudam ${ }^{8}$. O cuidado que se deve ter para não deturpar o dado ao calcular, por exemplo, a taxa de saída ou entrada separadamente para trabalho e estudo, é considerar no denominador o respectivo grupo populacional referente à população total do município: o total de pessoas que só trabalham ou que só estudam, para fins de comparação. Como exemplo, parte do banco de

\footnotetext{
${ }^{6}$ Para identificar nos microdados do Censo Demográfico de 2000 (IBGE) se a pessoa era estudante pode-se utilizar a variável v0429 igual 1 ou igual a 2 (frequência à escola ou creche). Para identificar se a pessoa trabalha, é preciso considerar conjuntamente as variáveis v0439, v0440, v0441, v0442 ou v0443 igual a 1 (que considera trabalho remunerado ou não-remunerado na semana de referência).

${ }^{7}$ Este total considera aqueles que possuem identificação clara de origem e destino e de trabalho e/ou estudo.

${ }^{8}$ Conforme consta em relatório elaborado por Moura et al. (2009).
} 
dados $^{9}$ disponibilizado online foi elaborado a partir desta estratégia para todos os municípios do Brasil em 2000, seguindo a estruturação da tabela 2.

Tabela 2 - Definição de dados sobre movimento pendular (saída) - 2000

\begin{tabular}{l|l}
\hline saida_total_00 & $\begin{array}{l}\text { Total de pessoas que saem do município por movimento pendular } \\
\text { em } 2000\end{array}$ \\
\hline saida_sotrab_00 & $\begin{array}{l}\text { Total de pessoas que saem do município por movimento pendular } \\
\text { em } 2000 \text { (só para trabalho) }\end{array}$ \\
\hline saida_soest_00 & $\begin{array}{l}\text { Total de pessoas que saem do município por movimento pendular } \\
\text { em } 2000 \text { (só para estudo) }\end{array}$ \\
\hline saida_trabest_00* & $\begin{array}{l}\text { Total de pessoas que saem do município por movimento pendular } \\
\text { em } 2000 \text { (para trabalho e/ou estudo) }\end{array}$ \\
\hline persaida_total_00 & $\begin{array}{l}\text { Taxa de Saída Total - Percentual de pessoas que saem do } \\
\text { município por movimento pendular em 2000 (sobre população total) }\end{array}$ \\
\hline persaida_00 & $\begin{array}{l}\text { Taxa de Saída Específica - Percentual de pessoas que saem do } \\
\text { município por movimento pendular em 2000 (sobre população que } \\
\text { trabalha e/ou estuda) }\end{array}$ \\
\hline persaida_sotrab_00 & $\begin{array}{l}\text { Taxa de Saída para Trabalho - Percentual de pessoas que saem do } \\
\text { município por movimento pendular em 2000 (só para trabalho por } \\
\text { população do município que só trabalha) }\end{array}$ \\
\hline persaida_soest_00 & $\begin{array}{l}\text { Taxa de Saída para Estudo - Percentual de pessoas que saem do } \\
\text { município por movimento pendular em 2000 (só para estudo por } \\
\text { população do município que só estuda) }\end{array}$ \\
\hline persaida_trabest_00* & $\begin{array}{l}\text { Percentual de pessoas que saem do município por movimento } \\
\text { pendular em 2000 (para trabalho e/ou estudo) sobre saída total }\end{array}$ \\
\hline
\end{tabular}

Fonte: Observatório das Metrópoles (2017). Banco de Dados do Movimento Pendular nos Municípios Brasileiros 2000 e 2010.

*Este percentual contribui para avaliar o peso (participação) daqueles que saem do município e estudam e trabalham simultaneamente sobre o total de pendulares, para os quais não é possível saber se o movimento pendular é para trabalho ou estudo, ou ambos.

Já em 2010, tivemos perguntas separadas, e esse pode ser considerado um grande avanço e abertura de potencialidades para os estudos ligados ao tema, principalmente sobre os aspectos referentes à localização das oportunidades educacionais e de trabalho, assim como as políticas públicas nessas áreas, conforme apontado na seção anterior.

Para os movimentos intermunicipais no Brasil, denominados de movimento pendular, utilizamos as variáveis do Censo Demográfico de 2010 que separa movimentos para estudo e trabalho. Nos microdados, as variáveis utilizadas para movimento em função de estudo e trabalho estão descritas na tabela 3.

\footnotetext{
${ }^{9}$ Disponível em:

https://drive.google.com/drive/folders/1t6cTYNWeYKyo1Y0s5DmOTanDTD0KgU7x?usp=sharing
} 
Tabela 3 - Variáveis de movimento pendular no Censo Demográfico Brasileiro 2010

\section{Estudo}

\begin{tabular}{|c|c|}
\hline V0636 & $\begin{array}{l}\text { MUNICÍPIO E UNIDADE DA FEDERAÇÃO OU PAÍS ESTRANGEIRO } \\
\text { QUE FREQUENTAVA ESCOLA (OU CRECHE): } \\
\text { 1- Neste município } \\
\text { 2- Em outro município } \\
\text { 3- Em país estrangeiro } \\
\text { Branco }\end{array}$ \\
\hline V6364 & $\begin{array}{l}\text { MUNICÍPIO QUE FREQUENTAVA ESCOLA (OU CRECHE) - código: } \\
\text { - A relação de códigos encontra-se no arquivo: } \\
\text { "Migração_Municípios_2010 V6254 V6264 V6364 V6604.xls" }\end{array}$ \\
\hline \multicolumn{2}{|r|}{ Trabalho } \\
\hline V0660 & $\begin{array}{l}\text { EM QUE MUNICÍPIO E UNIDADE DA FEDERAÇÃO OU PAÍS } \\
\text { ESTRANGEIRO TRABALHA: } \\
\text { 1- No próprio domicílio } \\
\text { 2- Apenas neste município, mas não no próprio domicílio } \\
\text { 3- Em outro município } \\
\text { 4- Em país estrangeiro } \\
\text { 5- Em mais de um município ou país } \\
\text { Branco }\end{array}$ \\
\hline V6604 & $\begin{array}{l}\text { EM QUE MUNICÍPIO TRABALHAVA - código: } \\
\text { - A relação de códigos encontra-se no arquivo: "Migração_Municípios_2010 } \\
\text { V6254 V6264 V6364 V6604.xls" }\end{array}$ \\
\hline
\end{tabular}

Fonte: Dicionário de Variáveis - Censo Demográfico de 2010 (IBGE).

As variáveis V6364 e V6604 são utilizadas para identificar o destino do movimento pendular (município) para estudo ou trabalho, respectivamente. A mudança ocorrida na forma de coletar a informação sobre movimento pendular foi muito importante para os estudos populacionais e urbanos, sobretudo para linhas de pesquisa que tratam sobre mercado de trabalho e oportunidades educacionais. Essa, inclusive, era uma das dificuldades encontradas por pesquisadores da área educacional, que restringia a tabulação e análise de dados sobre deslocamento para estudo, levando à ausência de estudos específicos sobre o tema, como tratado na primeira seção do texto.

Como exemplo, parte do banco de dados $^{10}$ disponibilizado online foi elaborado a partir destas variáveis para todos os municípios do Brasil em 2010, seguindo a estruturação da tabela 4.

Tabela 4 - Definição de dados sobre movimento pendular (saída) - 2010

\begin{tabular}{l|l}
\hline saida_total_10 & $\begin{array}{l}\text { Total de pessoas que saem do município para trabalhar e/ou } \\
\text { estudar em } 2010 \text { (quem faz os dois movimentos foi contado uma } \\
\text { vez) }\end{array}$ \\
\hline
\end{tabular}




\begin{tabular}{l|l}
\hline saida_trab_10 & Total de pessoas que saem do município para trabalhar em 2010 \\
\hline saida_est_10 & Total de pessoas que saem do município para estudar em 2010 \\
\hline saida_trabest_ig_10 & $\begin{array}{l}\text { Total de pessoas que saem do município para trabalhar e estudar } \\
\text { em outro município igual 2010 }\end{array}$ \\
\hline saida_trabest_dif_10 & $\begin{array}{l}\text { Total de pessoas que saem do município para trabalhar e estudar } \\
\text { em municípios diferentes 2010 }\end{array}$ \\
\hline persaida_total_10 & $\begin{array}{l}\text { Taxa de Saída Total - Percentual de pessoas que saem do } \\
\text { município para trabalhar e/ou estudar em 2010 sobre população } \\
\text { total (quem faz os dois movimentos foi contado uma vez) }\end{array}$ \\
\hline persaida_10 & $\begin{array}{l}\text { Taxa de Saída Específica - Percentual de pessoas que saem do } \\
\text { município para trabalhar e/ou estudar em 2010 sobre população } \\
\text { total (quem faz os dois movimentos foi contado uma vez) }\end{array}$ \\
\hline persaida_trab_10 & $\begin{array}{l}\text { Taxa de Saída para Trabalho - Percentual de pessoas que saem } \\
\text { do município para trabalhar em 2010 (sobre população ocupada) }\end{array}$ \\
\hline persaida_est_10 & $\begin{array}{l}\text { Taxa de Saída para Estudo - Percentual de pessoas que saem do } \\
\text { município para estudar em 2010 (sobre população estudante) }\end{array}$ \\
\hline
\end{tabular}

Fonte: Observatório das Metrópoles (2017). Banco de Dados do Movimento Pendular nos Municípios Brasileiros 2000 e 2010.

Diante das mudanças ocorridas, dois cuidados operacionais são importantes ao trabalhar com as informações de movimentos pendulares nos referidos anos $\mathrm{e}$ realizar a comparação entre os censos, conforme observa-se a seguir.

\section{A comparação entre os censos de 2000 e 2010 ao analisar trabalho e estudo}

Diante da exposição anterior, nota-se que há uma possibilidade de comparação entre os censos 2000 e 2010 ao analisar separadamente os motivos de trabalho e estudo, uma vez que é possível comparar quem só trabalha e faz movimento pendular em 2000 com os que em 2010 responderam à pergunta específica sobre trabalho; assim como é possível comparar quem só estuda e faz movimento pendular em 2000 com os que responderam em 2010 à pergunta específica sobre estudo.

Obviamente, nesse caso, deve-se reconhecer a limitação em relação aos valores de 2000, devido à perda daqueles que faziam movimento pendular e simultaneamente estudavam e trabalhavam. Sendo assim, a validade e confiabilidade desta comparação devem ser avaliadas em cada município ou aglomeração urbana específica, uma vez que, ao considerar os três grupos populacionais de movimento pendular, o peso deste último deve ser pequeno, para a comparação fazer sentido. Uma possibilidade é trabalhar com um percentual limite de até $10 \%$, usando o percentual nacional total como critério.

Apesar do avanço com as perguntas separadas, também é preciso ter cuidado quando o foco do estudo é analisar o movimento pendular total no município 
ou aglomeração urbana. Ou seja, geralmente quando se objetiva analisar a atratividade do município, sua área de influência, a articulação regional e a circularidade de pessoas, temas que geralmente são acionados ao considerar o movimento pendular, como visto anteriormente, busca-se analisar conjuntamente informações sobre trabalho e estudo - por exemplo, o total de pessoas que fazem movimento pendular para o município ou que dele saem (para trabalho e/ou estudo).

No caso do Censo 2010, é importante notar que não se deve apenas somar a quantidade de pessoas que declarou fazer movimento pendular para trabalho com a quantidade de pessoas que declarou o mesmo para estudo. Isso porque ao extrair informações separadamente para trabalho e estudo e atribuí-las a um município, pode-se duplicar indivíduos que realizam movimento pendular por ambos os motivos, uma vez que há pessoas que saem para trabalhar e estudar em municípios iguais e ainda aqueles que saem para trabalhar e estudar em municípios diferentes (mora em um, estuda em outro, trabalha em outro). Cunha et al. (2013, p. 456) também ressaltam a importância de "controlar a dupla contagem daqueles que fizeram tanto pendularidade por estudo quanto por trabalho". Nesses casos, quem faz os dois movimentos deve ser computado apenas uma vez em um banco de dados geral, como consta em Observatório das Metrópoles (2017).

A tabela 4 apresentada anteriormente esclarece tais variáveis. A variável saida_total é a soma dos que saem para trabalho e/ou para estudo, os que saem para ambos os motivos com destino a um mesmo município e os que saem para ambos os motivos para municípios diferentes. No banco de dados referido, essa população que sai para ambos os motivos, no cálculo percentual foi incluída tanto no trabalho como no estudo (quando se analisa separadamente), mas está discriminada nos números absolutos (saida_trabest_ig_10 e saida_trabest_dif_10).

\section{Análise de dados de movimento pendular em 2000 e 2010}

Para melhor compreensão das explicações metodológicas, vamos considerar como exemplo, a partir do banco de dados mencionado, as informações sobre movimento pendular do município de São Gonçalo, que faz parte da RMRJ (tabela 5). A escolha deste município deve-se ao fato de que em 2000 apresentou o maior número absoluto de saída de pessoas através do movimento pendular entre todos os municípios do Brasil. Em 2010, ficou em segundo lugar, perdendo apenas para o 
município de São Paulo, que teve um crescimento expressivo de saída de trabalhadores.

Tabela 5 - Dados de Movimento Pendular - Município de São Gonçalo (RJ) - 2000 e 2010

\begin{tabular}{|c|c|c|c|c|}
\hline \multicolumn{2}{|l|}{2000} & \multicolumn{3}{|c|}{2010} \\
\hline Pop. Total & 891.119 & \multicolumn{2}{|l|}{ Pop. Total } & 999.728 \\
\hline \multicolumn{5}{|c|}{ Saída } \\
\hline Saída total & 149.186 & \multicolumn{2}{|l|}{ Saída total } & 196.317 \\
\hline Saída só trabalho & 122.072 & \multicolumn{2}{|l|}{ Saída só trabalho } & 162.268 \\
\hline Saída só estudo & 15.134 & \multicolumn{2}{|l|}{ Saída só estudo } & 22.735 \\
\hline Saída trab. e/ou est. & 11.979 & $\begin{array}{l}\text { Saída trab. e est. Munic }= \\
\text { Saída trab. e est. Munic } \neq\end{array}$ & $\begin{array}{l}6.901 \\
4.414\end{array}$ & 11.315 \\
\hline Saída trab. e/ou est. $(\%)^{(1)}$ & 8,0 & \multicolumn{2}{|c|}{ Saída trab. e est. (\%) ${ }^{(1)}$} & 5,8 \\
\hline Taxa de saída total (\%) & 16,7 & \multicolumn{2}{|l|}{ Taxa de saída total (\%) } & 19,6 \\
\hline Taxa de saída específica (\%) & 26,6 & \multicolumn{2}{|l|}{ Taxa de saída específica (\%) } & 28,7 \\
\hline Taxa de saída só trabalho (\%) & 39,6 & \multicolumn{2}{|l|}{$\begin{array}{l}\text { Taxa de saída trabalho (\%) } \\
\text { [162.268+11.315] }\end{array}$} & 38,8 \\
\hline Taxa de saída só estudo (\%) & 6,9 & \multicolumn{2}{|l|}{$\begin{array}{l}\text { Taxa de saída estudo (\%) } \\
\text { [22.735+11.315] }\end{array}$} & 11,9 \\
\hline
\end{tabular}

\section{Entrada}

\begin{tabular}{l|r|l|r}
\hline Entrada total & 18.135 & Entrada total & 31.686 \\
\hline Entrada só trabalho & 13.989 & Entrada só trabalho & 24.187 \\
\hline Entrada só estudo & 2.774 & Entrada só estudo & 7.027 \\
\hline Entrada trab. e est. & 1.372 & Entrada trab. e est. & 471 \\
\hline Entrada Trab. e Est. (\%) ${ }^{(1)}$ & 7,6 & - & - \\
\hline Taxa de entrada total (\%) & 2,0 & Taxa de entrada total (\%) & 3,2 \\
\hline Taxa de entrada específica & 3,2 & Taxa de entrada específica (\%) & 4,6 \\
\hline $\begin{array}{l}\text { Taxa de entrada só trabalho } \\
(\%)\end{array}$ & 4,5 & $\begin{array}{l}\text { Taxa de entrada trabalho (\%) } \\
{[24.187+471]}\end{array}$ & 5,5 \\
\hline $\begin{array}{l}\text { Taxa de entrada só estudo } \\
\text { (\%) }\end{array}$ & 1,3 & $\begin{array}{l}\text { Taxa de entrada estudo (\%) } \\
\text { [7 } 027+471]\end{array}$ & 2,6 \\
\hline
\end{tabular}

Fonte: Observatório das Metrópoles (2017). Banco de Dados do Movimento Pendular nos Municípios Brasileiros 2000 e 2010.

(1) Estes percentuais, distintamente dos demais, não são sobre a população que trabalha e/ou estuda, mas sobre o total de pessoas que realiza movimento pendular.

Nota: Os dados em itálico são comparáveis, os demais são aproximáveis em termos de comparação, quanto menor for o percentual de (1).

Primeiramente, vamos tratar sobre a análise conjunta, sobre o total de pessoas que faz movimento pendular. Conforme consta na tabela 5, de 2000 para 2010, houve um aumento considerável dos movimentos pendulares no município de São Gonçalo, tanto de entrada como de saída para ambos os motivos. A quantidade de saída total (para trabalho e estudo), em números absolutos passou de 149.186 
em 2000 para $196.317^{11}$ no ano de 2010 (um aumento de 31,6\%). O quantitativo de entradas também apresentou aumento: em 2000 entraram 18.135 pessoas no município, em 2010, 31.686 entraram para trabalhar e/ou estudar (o aumento foi expressivo: $74,7 \%$ ).

No caso de São Gonçalo, acompanhando o aumento em números absolutos, se considerarmos estes valores em relação à população total do município (taxa de saída total), também houve aumento na proporção de pendulares, de $16,7 \%$ em 2000 para 19,6\% em 2010 em relação à saída de pessoas. Entretanto, a fim de refinar a análise, consideramos ser mais apropriado avaliar a proporção de pessoas que saem em relação ao potencial real de mobilidade, que será a população residente no município que trabalha e/ou estuda - o que irá abarcar mais diretamente a população ativa no mercado de trabalho ou no sistema educacional. Obviamente, a proporção irá aumentar em razão da diminuição no denominador, por considerar uma população mais restrita. Nesse caso, a proporção de saída, denominada taxa de saída específica ${ }^{12}$ foi de 26,6\% em 2000 aumentando para $28,7 \%$ em 2010 no município de São Gonçalo. No que se refere às entradas, a taxa de entrada específica ${ }^{13}$ aumentou de $3,2 \%$ para $4,6 \%$ de 2000 a 2010 considerando essa população mais refinada no denominador.

Sobre as informações de saída e entrada por motivos, vamos analisar a seguir apenas as informações sobre saída, devido aos limites deste artigo. No que se refere ao motivo de trabalho, em 2000 havia 122.072 pessoas que saíam de São Gonçalo para trabalhar em outro município (estes só eram trabalhadores, não estudantes); já em 2010, a saída estrita para trabalho subiu para 162.268 pessoas, o que nos permite afirmar que houve aumento do movimento pendular de saída do município para trabalho. No que se refere ao motivo de estudo, havia 15.134 estudantes que saíam de São Gonçalo para estudar em outro município em 2000; em 2010 o número destes estudantes elevou-se para 22.735. Ou seja, tanto os movimentos de saída para trabalho como para estudo aumentaram em números absolutos.

\footnotetext{
11 Para este total, quem faz os dois movimentos foi contado apenas uma vez. Para obter essa informação conjunta em 2010 (a população pendular total), não se pode ir nas variáveis separadas de trabalho e estudo e somar as pessoas que declararam realizar tais movimentos; é preciso separar o grupo de pessoas que realiza os dois movimentos simultaneamente e computá-los apenas uma vez, para não duplicar.

${ }_{12}$ Taxa de saída específica - Percentual de pessoas que saem do município por movimento pendular em 2010 (sobre população que trabalha e/ou estuda).

13 Taxa de entrada específica - Percentual de pessoas que entram no município por movimento pendular em 2010 (sobre população que trabalha e/ou estuda).
} 
Entretanto, no ano 2000 eram 11.979 que faziam movimento pendular de saída do município, para os quais não sabemos se era para trabalhar e/ou estudar. Estes correspondiam a $8 \%$ do total da população que faz movimento pendular de saída (11.979/149.379), um percentual abaixo do percentual nacional (10\%). Em 2010, como já havia perguntas separadas, 6.901 saíam para trabalhar e estudar no mesmo município de destino e 4.414 faziam movimento pendular entre três municípios, ou seja: morava em um, trabalhava em outro e estudava em um terceiro. A grande diferença de 2000 em relação a 2010 é que para esses 11.979 que trabalham e/ou estudavam em 2000, não se sabe se o movimento é para trabalho ou estudo ou ambos. Já para os 11.315 (4.414+6.901) de 2010 podemos incluí-los tanto no total de trabalho quanto no de estudo, ao realizar estudos separados - isso significa que em estudos separados (trabalho ou estudo), não é preciso preocuparse com a duplicação de indivíduos.

Em 2000, 39,6\% da população que só trabalhava residente do município de São Gonçalo saía para trabalhar em outro. Em 2010, 38,8\% da população ocupada total saía para trabalhar (inclusive os que trabalham e estudam em outro município). De qualquer forma, pode-se dizer que houve uma pequena diminuição, até porque os valores de 2000 estão subestimados (por não considerarmos os que trabalham e estudam nesse caso).

Já em relação ao estudo, 6,9\% da população que só estudava residente do município de São Gonçalo saía para estudar em outro em 2000. Em 2010, 11,9\% de todos os estudantes faziam o movimento pendular para estudo - o que também sugere um aumento desta participação.

\section{Considerações Finais}

Os movimentos pendulares fazem parte dos processos de mobilidade espacial e o enfoque a partir desse conceito contribui para ressaltar a dimensão social e espacial do fenômeno, que está bastante ligado às potencialidades e aos constrangimentos da estrutura urbana - acesso à moradia, trabalho, educação, lazer - e aos aspectos socioculturais das pessoas e dos lugares de origem e destino. Os dados sobre mobilidade espacial, ao mesmo tempo em que fornecem um aporte empírico importante para a compreensão da realidade urbano-regional, também suscitam uma fundamentação teórico-conceitual que, conjuntamente, permitem 
debater temas atuais sobre essa realidade, tanto em termos conceituais e operacionais, como também no que se refere à proposição de intervenção.

Quanto às potencialidades das informações censitárias sobre mobilidade espacial, são de grande relevância para os estudos urbano-regionais, geográficos e demográficos, e, em termos sociológicos, também auxiliam na compreensão das diferentes estratégias por parte da população para acessar uma estrutura de oportunidades desigualmente distribuída no espaço.

Mesmo diante das potencialidades quanto aos processos e fenômenos que podem expressar, os dados geralmente utilizados também esbarram em limitações de caráter metodológico, devido às formas de operacionalizar os processos de mobilidade e às fontes de dados disponíveis, e até mesmo os cuidados necessários no tratamento e análise dos dados, sobretudo para fins comparativos no tempo.

Uma limitação que deve ser considerada está no fato de que a mobilidade espacial cotidiana, por exemplo, pode ocorrer por inúmeros motivos, o que a faz ultrapassar os dados estritos sobre movimentos pendulares, que devem ser considerados como uma proxy de tal mobilidade.

A questão da escala também precisa ser observada. Ao considerar sua dimensão geográfica e as escalas territoriais, os movimentos pendulares geralmente são analisados numa perspectiva urbano-regional, já que implicam em ultrapassar as fronteiras político-administrativas. Entretanto, também seria importante considerar a escala intraurbana. Na escala da cidade, é possível saber de onde as pessoas saem e avaliar, por exemplo, a distribuição da população pelos lugares de origem na cidade, porém há uma limitação em não sabermos para qual lugar o indivíduo vai na cidade de destino. Nesse sentido, pelo menos a análise do lugar de origem na cidade é possível ser feita. Sendo assim, uma análise interescalar pode ser desafiadora, mas provavelmente será bastante produtiva, e os microdados censitários permitem tal associação na cidade de origem.

Além disso, também há questões ligadas à temporalidade dos processos de deslocamento que demandam maior compreensão. No caso do censo 2010, uma análise combinada com o tempo de deslocamento para trabalho também é possível e muito pertinente ${ }^{14}$.

No que se refere à abordagem operacional, observa-se que os dados referentes ao movimento pendular apresentam considerável riqueza empírica para

\footnotetext{
14 No próximo Censo (2020), além da pergunta sobre o tempo de deslocamento, será questionado também sobre o principal meio de transporte utilizado para chegar ao local de trabalho, o que amplia as possibilidades de análise e compressão do fenômeno e de sua relação com a dinâmica urbana.
} 
trabalhar com os processos sociais, espaciais e econômicos colocados acima. Por isso, a realização de perguntas no censo demográfico sobre esta dimensão e as possibilidades de correlacioná-las com as demais dimensões sociais, econômicas e demográficas são de grande relevância.

Sendo o censo a maior fonte de dados acerca da mobilidade da população, tanto no que se refere aos tipos de informação quanto à abrangência, é preciso defender sua realização de forma ampla e qualificada, fato que tem ido à contramão das informações divulgadas pelo IBGE (2019) sobre a realização do próximo Censo Demográfico Brasileiro, em 2020, que pretende reduzir determinados quesitos dos questionários aplicados à população, entre eles alguns que dizem respeito à mobilidade espacial. A redução é explicada pela atual diretoria do instituto a partir de critérios generalizados como qualidade do levantamento e redução de custos e tempo de resposta, afirmando que seria uma aproximação ao que é aplicado em outros países. Entretanto, essa justificativa vem sendo questionado por diversas instituições, associações, pesquisadores, estudiosos e especialistas das diferentes áreas, já que no Brasil as pesquisas auxiliares não englobam os demais quesitos, entre outras questões. Portanto, é preciso acompanhar os desdobramentos da realização desta grande operação de pesquisa.

Apesar dos desafios, espera-se que este trabalho, juntamente com os dados disponibilizados nos bancos referenciados, possa contribuir para os estudos a respeito dos processos de mobilidade espacial cotidiana no Brasil por motivos de trabalho e estudo. Para lidar adequadamente com essas informações, alguns cuidados são necessários ao tratar os dados censitários, sobretudo no que se refere a possibilidades comparativas entre os Censos Demográficos Brasileiros de 2000, 2010 e, esperamos, o Censo de 2020.

\section{REFERÊNCIAS}

ALVES, F.; LANGE, W.; BONAMINO, A. (2010). "A Geografia Objetiva de Oportunidades Educacionais na Cidade do Rio de Janeiro". In: RIBEIRO, L. C. de Q.; KOSLINSKI, M. C.; ALVES, F.; LASMAR, C. (Orgs.) Desigualdades urbanas, desigualdades escolares. Rio de Janeiro: Letra Capital: Observatório das Metrópoles: IPPUR/UFRJ.

BAENINGER, R. (1998). Deslocamentos populacionais, urbanização e regionalização. Revista Brasileira de Estudos Populacionais. Brasília, 15 (2), p. 67-78.

BEAUJEU-GARNIER, J. (1980). Geografia da população. São Paulo: Companhia Editora Nacional.

BOURDIEU, P. (1997). "Efeitos do Lugar". In: BOURDIEU, P., A Miséria do Mundo. Petrópolis: Ed. Vozes. p. 159-166. 
BRAGA, F.; MATOS, R. (2017). Quem são os migrantes das metrópoles? Uma análise comparativa das pessoas que entraram e saíram das regiões metropolitanas brasileiras. Revista de Geografia e Ordenamento do Território (GOT). n.ำ11, p. 59-81.

BRITO, F. (2009). As migrações internas no Brasil: um ensaio sobre os desafios teóricos recentes. Texto para discussão ํㅜ 366. Belo Horizonte: UFMG/Cedeplar.

CUNHA, J. M. P. (2002). Urbanización, redistribución espacial de la población y transformaciones socioeconómicas en América Latina. Santiago de Chile: CELADE-FNUAP, Serie Población y Desarrollo (30).

CUNHA, J. M. P.; JAKOB, A. A. E.; JIMENEZ, M. A.; TRAD, I. L. (2006). Expansão metropolitana, mobilidade espacial e segregação nos anos 90: o caso da RM de Campinas. In: CUNHA, J. M. P. (Org.). In: Novas Metrópoles Paulistas: população, vulnerabilidade e segregação. 1ed. v. 1. Campinas: Editora da Unicamp.

CUNHA, J. M. P.; STOCO, S.; DOTA, E. M.; NEGREIROS, R.; MIRANDA, Z. A. I. (2013). A mobilidade pendular na Macrometrópole Paulista: diferenciação e complementaridade socioespacial. Cadernos Metrópole. São Paulo, v. 15, n. 30, pp. 433-459.

GALSTER, G. C.; KILLEN, S. P. (1995). The Geography of Metropolitan Opportunity: A Reconnaissance and Conceptual Framework. Housing Policy 6, N.1: 1995. p. 7-43.

INSTITUTO BRASILEIRO DE GEOGRAFIA E ESTATÍSTICA (IBGE). (2002). Censo Demográfico 2000: Documentação dos Microdados da Amostra. Rio de Janeiro: Instituto Brasileiro de Geografia e Estatística.

(2012). Censo Demográfico 2010: Educação e deslocamento. Resultados da amostra. Rio de Janeiro: Instituto Brasileiro de Geografia e Estatística. ISSN 0104-3145.

(2012). Censo Demográfico 2010: Resultados da amostra. Rio de Janeiro: Instituto Brasileiro de Geografia e Estatística; 2010. Disponível em: <http://censo2010.ibge.gov.br/resultados>. Acesso em: 13 jul. 2015.

INSTITUTO BRASILEIRO DE GEOGRAFIA E ESTATÍSTICA (IBGE). 2019. Agência de Notícias. Disponível em: $<$ https://agenciadenoticias.ibge.gov.br/media/com mediaibge/arquivos/fa76b81a7089b4f92d 2af2b04394f12f.pdf>; <https://agenciadenoticias.ibge.gov.br/agencia-noticias/2012-agenciade-noticias/noticias/24705-ibge-define-tamanho-dos-questionarios-do-censo-2020>. Acesso em 11 jun. 2019.

JARDIM, A. P. (2011). Reflexões sobre a mobilidade pendular. In: OLIVEIRA, L. A. P.; OLIVEIRA, A. T. R. Reflexões sobre os Deslocamentos Populacionais no Brasil. Rio de Janeiro: IBGE, Estudos e Análises 1.

KAZTMAN, R. (1999). Activos y Estructuras de Oportunidades: un estudio sobre las raíces de la vulnerabilidad social en Uruguay (Coordinador). CEPAL/UNDP: Uruguay.

LAGO, L. C. (2007). A "periferia" metropolitana como lugar do trabalho: da cidade-dormitório à cidade plena. Cadernos IPPUR. Rio de Janeiro, UFRJ, ago/dez.

LEE, E. S. (1980). Uma teoria sobre a migração. In: MOURA, H. A. de (Coord.). Migração interna: textos selecionados. Fortaleza: Banco do Nordeste do Brasil.

LIMA, W. M. (2015). Novas mobilidades, espaço de vida e desempenho escolar: o caso dos estudantes de ensino médio no município de Natal - RN. Dissertação de Mestrado. Natal, Universidade Federal do Rio Grande do Norte (UFRN).

LOBO, C. (2016). Mobilidade pendular e a dispersão espacial da população: evidências com base nos fluxos com destino às principais metrópoles brasileiras. Caderno de Geografia, v.26, n.45. p. 285-298.

MOURA, R.; BRANCO, M. L. G. C.; FIRKOWSKI, O. L. C. F. (2005). Movimento Pendular e Perspectivas de Pesquisas em Aglomerados Urbanos. São Paulo em Perspectiva, v. 19, n. 4, p. 121-133.

MOURA, R. (coord.). (2009). Movimento pendular da população na Região Sul. Observatório das Metrópoles: Relatório de atividades, março/2009. Disponível em: $<$ http://www.observatoriodasmetropoles.net/images/abook file/pendular sul.pdf $>$. Acesso em: 12 jun. 2018.

MOURA, R.; DELGADO, P.; COSTA, M.A. (2013). Movimento pendular e políticas públicas: algumas possibilidades inspiradas numa tipologia dos municípios brasileiros. In BOUERI, R.; COSTA, M. A. (ED.). (2013). Brasil em Desenvolvimento. Estado, planejamento e políticas públicas. V. 3, cap. 22. Instituto de Pesquisa Econômica Aplicada. Brasília: Ipea. 
OBSERVATÓRIO DAS METRÓPOLES. (2017). Banco de Dados do Movimento Pendular nos Municípios Brasileiros 2000 e 2010. Disponível em:

$<$ https://drive.google.com/drive/folders/1t6cTYNWeYKyo1Y0s5DmOTanDTD0KgU7x?usp=s haring>. Acesso em: 12 jun. 2019.

OLIVEIRA, A. T. R. (2011). Abordagens teóricas a respeito do fenômeno migratório. In: OLIVEIRA, L. A. P.; OLIVEIRA, A. T. R. Reflexões sobre os Deslocamentos Populacionais no Brasil. Rio de Janeiro: IBGE, Estudos e Análises 1.

PEREIRA, R. H. M. (2006). Polarização urbana e mobilidade da população: O caso dos deslocamentos pendulares na rede pública de ensino médio do Distrito Federal. In: ENCONTRO NACIONAL DE ESTUDOS POPULACIONAIS, 15., Caxambu. Anais... Belo Horizonte: ABEP, 2006. p. 1-18.

PEREIRA, R. H. M.; HERRERO, V. (2009). Mobilidade pendular: uma proposta teóricometodológica. IPEA. Texto para Discussão, n. 1.395. Rio de Janeiro: Ipea, mar. 2009. Disponível em: <http://goo.gl/Kz6f2Z>. Acesso em 15 ago. 2017.

RIGOTTI, J. I. R. (2008). A (re) distribuição espacial da população brasileira e possíveis impactos sobre a metropolização. In: XXXII ENCONTRO ANUAL DA ANPOCS, 32., Caxambu. Anais... ANPOCS, 2008, p. 1-26.

RODRIGUEZ, J. (2011). La ampliación de la centralidad histórica em Santiago de Chile. São Paulo: Cadernos Metrópole, vol. 13, n. 25, p. 45-68.

SANTOS, M. (2014). Metamorfoses do Espaço Habitado: Fundamentos Teóricos e metodológicos da geografia. 6. ed. 2. reimp. - São Paulo: EDUSP.

SILVA, E. T. (2013). Estrutura urbana e mobilidade espacial nas metrópoles. Rio de Janeiro: Letra Capital.

SINGER, P. (1977). Economia Política da Urbanização. São Paulo: Brasiliense, 4ª edição. SISTEMA DE SELEÇÃO UNIFICADA (SISU). (2016). Conhecendo o SISU. Disponível em: <http://sisu.mec.gov.br/tire-suas-duvidas\#conhecendo>. Acesso em: 28 fev. 2016.

TAVARES, E. (2012). Estrutura urbana e movimentos populacionais intrametropolitanos. In: XVIII ENCONTRO NACIONAL DE ESTUDOS POPULACIONAIS, 18., Águas de Lindóia. Anais.... Águas de Lindóia: ABEP, 2012, p. 1-21.

TAVARES. J. M. S. (2016). Movimentos Pendulares de Estudantes na Região Norte Fluminense. Dissertação de Mestrado. Campos dos Goytacazes, Universidade Federal Fluminense (UFF).

TAVARES, E.; TAVARES, J. M. S. (2014). Movimentos Pendulares de Estudantes no Norte Fluminense: o papel de Campos dos Goytacazes. In: II SEMINÁRIO NACIONAL DE PLANEJAMENTO E DESENVOLVIMENTO, 2., Florianópolis. Anais... Florianópolis: PPGPGP, 2014. p. 1-19.

URRY. J. (2007). Mobilities. Cambridge: Polity Press.

WOOD, C. H. (1982). Equilibrium and historical - structural perspectives on migration. International Migration Review, 16 (2): p. 298-318.

\section{NOTAS DE AUTOR}

\section{CONTRIBUIÇÃO DE AUTORIA} Erica Tavares da Silva Rocha - Concepção, levantamento de dados, análise de dados, elaboração do manuscrito,
participação ativa da discussão dos resultados, revisão e aprovação da versão final do trabalho.
Jéssica Monteiro da Silva Tavares - Elaboração do manuscrito, análise de dados, discussão dos resultados, revisão e
aprovação da versão final do trabalho.

\section{FINANCIAMENTO}

Não se aplica

CONSENTIMENTO DE USO DE IMAGEM

Não se aplica

APROVAÇ̃̃o DE COMITÊ DE ÉTICA EM PESQUISA

Não se aplica

CONFLITO DE INTERESSES

Não há 


\section{LICENÇA DE USO}

Este artigo está licenciado sob a Licença Creative Commons CC-BY. Com essa licença você pode compartilhar, adaptar, criar para qualquer fim, desde que atribua a autoria da obra.

\section{HISTÓRICO}

Recebido em: 04-07-2018

Aprovado em: 19-06-2019 